\title{
PROSPEK PEMBESARAN IKAN BAWAL (Colossoma macropomum) DI DESA SUKOSARI KECAMATAN BELITANG KABUPATEN OKU TIMUR
}

\author{
Yudi Zuriah (Dosen STIPER SRIWIGAMA)
}

\begin{abstract}
The purpose of this study is to: (1) To find out how much the cost of production and acceptance of the enlargement of pomfret (Colossoma macropomum) in one production process, (2) To find out how the value of the feasibility of enlargement of bawal fish (Colossoma macropomum) in one time production process. This research was conducted in Sukosari Village, Belitang District, OKU Timur Regency. Determination of research location is done purposively or purposely, with the consideration that in Sukosari Village is one of the villages that develop bawal fish enlargement farming and the area has enough population in the research criteria. The study was conducted in February 2015 until it was completed. This study found that the average cost of revenues and revenues of pomfret fish breeding in the production period of 4 months, obtained revenue in pomfret breeding business amounted to Rp 37.322 .467 / process, while the income from the business of raising fish pomfret $R p 11.352 .433$ / process. The analysis of $R / C$ ratio obtained from the enlargement of pomfret fish in 4 months is 1.4, which means that every one rupiah sacrificed will be obtained by the receipt of 1.4 so the enlargement of pomfret is said to be profitable. ROI analysis represents the rate of return on capital where ROI on the business of fish bawal enlargement is $42 \%$.
\end{abstract}

Key Words : Colossoma macropomum, Fish cultivation, Income.

\section{PENDAHULUAN}

\section{A. Latar Belakang}

Pertanian merupakan sektor ekonomi yang utama di negara-negara berkembang. Peranan sektor pertanian dalam pembangunan ekonomi suatu negara menduduki posisi yang sangat penting. Indonesia memiliki luas lahan dan kondisi iklim yang sangat potensial untuk dikembangkan sebagai usaha pertanian. Kegiatan pertanian mencakup lima sub sektor pertanian yaitu pertanian tanaman pangan, perkebunan, perikanan, peternakan dan kehutanan. Salah satu sub sektor kegiatan pertanian adalah perikanan. Indonesia memiliki lahan perikanan air tawar yang cukup besar (Badan Pusat Statistik Republik Indonesia, 2007).

Ikan bawal merupakan salah satu jenis ikan air tawar yang banyak diminati dikarenakan beberapa keunggulan yang dimilikinya seperti warna merah yang menarik dan selintas mirip ikan kakap merah, rasanya yang khas membuat bawal enak diolah dengan cara apapun dan harganya relatif lebih murah sehingga lebih terjangkau oleh semua kalangan. Prospek pengembangan budidaya ikan bawal di Indonesia cukup cerah. Keadaan iklim dan lahan perikanan air tawar yang luas merupakan faktor pendukung dalam pengembangan agribisnis di Indonesia, salah satunya komoditas ikan bawal (Sucipto dan Prihartono, 2005).
Ikan patin, bawal dan nila adalah andalan perikanan budidaya air tawar di provinsi Sumatera Selatan. Ketiga komoditas andalan provinsi ini sebagian besar dipelihara dalam wadah kolam dan karamba. Beberapa wilayah telah mengembangkan pemeliharaan budidaya ikan air tawar dengan metode kolam air deras yang dapat memelihara ikan dengan kepadatan tinggi. Sebagian wilayah lainnya juga telah mengembangkan teknik budidaya dengan metode karamba jaring tancap.

Sentra perikanan budidaya air tawar provinsi Sumatera Selatan berada di beberapa kabupaten yaitu kabupaten Musi Rawas. Mulai dari budidaya kolam, karamba, jaring apung dan minapadi ada di kabupaten ini. Bahkan menjadi penghasil terbesar pada setiap jenis budidayanya kecuali budidaya jaring apung. Selain Musi Rawas, sentra budidaya air tawar terdapat pula di OKU Timur, Lubuk Linggau, Pagaralam, Lahat, OKU dan OKU Selatan.

Produksi perikanan budidaya air tawar provinsi Sumatera Selatan termasuk stabil. Produksinya setiap tahun mengalami peningkatan. Sempat disalip produksi oleh Sumatera Barat pada tahun 2008 namun di tahun selanjutnya Sumatera Selatan tetap yang nomor satu di pulau Sumatera. Pada Tahun 2009 produksi perikanan budidaya air tawar mencapai 110.390,5 ton dan pada tahun 2010 sebesar $151.927,7$ ton. Berdasarkan data 
produksi perikanan di provinsi Sumatera Selatan sebagai mana pada tabel 1 berikut ini :

Tabel 1. Produksi Perikanan Kabupaten/Kota di Sumatera Selatan.

\begin{tabular}{|c|c|c|c|c|c|}
\hline \multirow{3}{*}{ No } & \multirow{3}{*}{$\mathrm{Kab} / \mathrm{Kota}$} & \multicolumn{3}{|c|}{ Produksi(Ton) } & \multirow[b]{3}{*}{ Budidaya } \\
\hline & & \multicolumn{3}{|c|}{ Perikanan Tangkap } & \\
\hline & & Laut & $\begin{array}{c}\text { Peraiaran } \\
\text { Umum }\end{array}$ & Total & \\
\hline 1 & Palembang & - & 1.510 .70 & 1.510 .70 & 8.057 .40 \\
\hline 2 & Musi Banyuasin & - & 8.099 .20 & 8.099 .20 & 8.247 .00 \\
\hline 3 & Banyu Asin & 33.817 .90 & 9.117 .60 & 42.935 .50 & 11.301 .20 \\
\hline 4 & Ogan Komering Ilir & 7.058 .80 & 9.868 .50 & 16.927 .30 & 72.516 .60 \\
\hline 5 & Ogan Ilir & - & 4.182 .20 & 4.182 .20 & 10.293 .80 \\
\hline 6 & Ogan Komering Ulu & - & 4.278 .90 & 4.278 .90 & 11.066 .50 \\
\hline 7 & OKU Timur & - & 1.427 .50 & 1.427 .50 & 15.763 .20 \\
\hline 8 & OKU Selatan & - & 1.222 .70 & 1.222 .70 & 10.940 .00 \\
\hline 9 & Muara Enim & - & 4.705 .90 & 4.705 .90 & 4.872 .40 \\
\hline 10 & Prabumulih & - & 482.40 & 482.40 & 2.352 .70 \\
\hline 11 & Musi Rawas & - & 1.801 .00 & 1.801 .00 & 21.371 .90 \\
\hline 12 & Lubuk Linggau & - & 241.60 & 241.60 & 15.707 .80 \\
\hline 13 & Lahat & - & 2.527 .30 & 2.527 .30 & 10.043 .50 \\
\hline
\end{tabular}

Sumber : Dinas Kelautan dan Perikanan Sumatera Selatan 2010.

Kabupaten OKU Timur merupakan Kabupaten yang berbasis pertanian, selain sebagai lubung beras Kabupaten OKU Timur juga sebagai penghasil ikan konsumsi, sumber ikan di wilayah tersebut didapat dengan tiga sumber yaitu ikan hasil budidaya, ikan hasil pembesaran dan ikan yang berasal dari hasil tangkapan liar, perkembangan usaha di perikanan sangat baik hal tersebut dikarenakan Kabupaten OKU Timur memiliki potensi wilayah perairan yang cukup luas, disekitar Belitang sumber air didapat melalui saluran irigasi sedangkan di wilayah lain khususnya sumber air didapat dari saluran air sungai komering, atas dasar potensi tersebut perkembangan usaha perikanan baik budidaya, pembesaran maupun tangkapan dari perairan bebas cukup memadai (BPPKP OKU Timur, 2012).

Hasil perikanan darat yang bersumber dari usaha kolam juga belum banyak berkembang di OKU Timur. Masyarakat lebih banyak melakukan usaha penangkapan ikan, baik di sungai maupun di sawah. Hal ini didukung oleh kondisi Kabupaten OKU Timur yang banyak dialiri sungai, baik sungai besar seperti sungai Komering dan sungai-sungai kecil lainnya Data tahun pada 2006 menunjukkan bahwa produksi ikan perairan umum menghasilkan produksi sebesar 346.27 ton sedangkan perikanan budidaya menghasilkan 7.034 ton. Ikan budidaya tersebut di produksi dari kolam seluas 830 hektar, sawah 1.245 hektar dan keramba sebesar 153 hektar. Sebagaimana pada tabel 2 berikut:

Tabel 2. Produksi Ikan Berdasarkan Kecamatan di Kabupaten OKU Timur.

\begin{tabular}{|c|c|c|c|c|}
\hline \multirow{2}{*}{ Nama Kecamatan } & \multicolumn{3}{|c|}{ Luas Area Tempat Budidaya Perikanan } & \multirow{2}{*}{$\begin{array}{l}\text { Total Produksi } \\
\text { (ton) }\end{array}$} \\
\hline & Kolam (ha) & Sawah (ha) & Keramba (ha) & \\
\hline Martapura & 7,21 & 4,85 & - & 75,91 \\
\hline Bunga Mayang & 10,50 & 7,88 & - & 69,53 \\
\hline Jayapura & 5,90 & 6,70 & - & 0,58 \\
\hline B P Peliung & 19,97 & 7,35 & - & 36,35 \\
\hline Buay Madang & 130,81 & 256,25 & - & 706,80 \\
\hline Buay Madang Timur & 65,41 & 128,13 & - & 1333,94 \\
\hline Madang Suku II & 39,17 & - & 18,86 & 267,15 \\
\hline Madang Suku III & 19,57 & - & 9,43 & 225,98 \\
\hline Madang Suku I & 131,16 & 38,86 & 20,96 & 740,03 \\
\hline Belitang I & 182,58 & 345,53 & - & 306,51 \\
\hline Belitang III & 48,27 & 67,21 & - & 128,08 \\
\hline Belitang II & 28,86 & 43,06 & - & 15,33 \\
\hline Semendawai Suku III & 33,01 & 127,00 & - & 99,02 \\
\hline Semendawai Timur & 30,17 & 95,80 & - & 258,81 \\
\hline Cempaka & 15,74 & - & 103,75 & 526,01 \\
\hline Semendawai Barat & 61,68 & 116,42 & - & $2.587,96$ \\
\hline Total & 830,00 & 1245,04 & 153,00 & $7.380,99$ \\
\hline
\end{tabular}

Sumber: Dinas Pertanian Tanaman Pangan, Perikanan dan Peternakan Kabupaten OKU Timur.

Potensi perikanan air tawar yang dimiliki oleh Desa Sukosari terutama pada usaha pembesaran ikan bawal telah memberikan peluang bisnis bagi petani yang mengusahakannya. Hasil ikan yang unggul dan berkualitas sangat diharapkan dari petani dari pembenih agar tingkat kematian pada saat pembesaran dapat diminimalisir. Untuk memperoleh benih yang unggul dibutuhkan berbagai faktor-faktor produksi yang mendukung proses produksinya. Usaha pembesaran ikan bawal di Desa Sukosari telah berjalan lebih kurang selama lima tahun. Selama proses produksi usaha pembesaran berjalan, petani perlu memperhatikan faktorfaktor produksi yang dapat mempengaruhi arus keuangan dan pendapatan yang akan diperoleh serta keberlanjutan usahanya.

\section{B. Rumusan Masalah}

1. Berapa besar biaya produksi dan penerimaan petani dari pembesaran ikan bawal (Colossoma macropomum) dalam satu kali proses produksi.

2. Apakah usahatani pembesaran ikan bawal (Colossoma macropomum) layak untuk dikembangkan. 


\section{Tujuan dan Kegunaan}

1. Untuk mengetahui berapa besar biaya produksi dan penerimaan dari pembesaran ikan bawal (Colossoma macropomum) dalam satu kali proses produksi.

2. Untuk mengetahui berapa nilai kelayakan pembesaran ikan bawal (Colossoma macropomum) dalam satu kali proses produksi.

\section{Model Pendekatan}

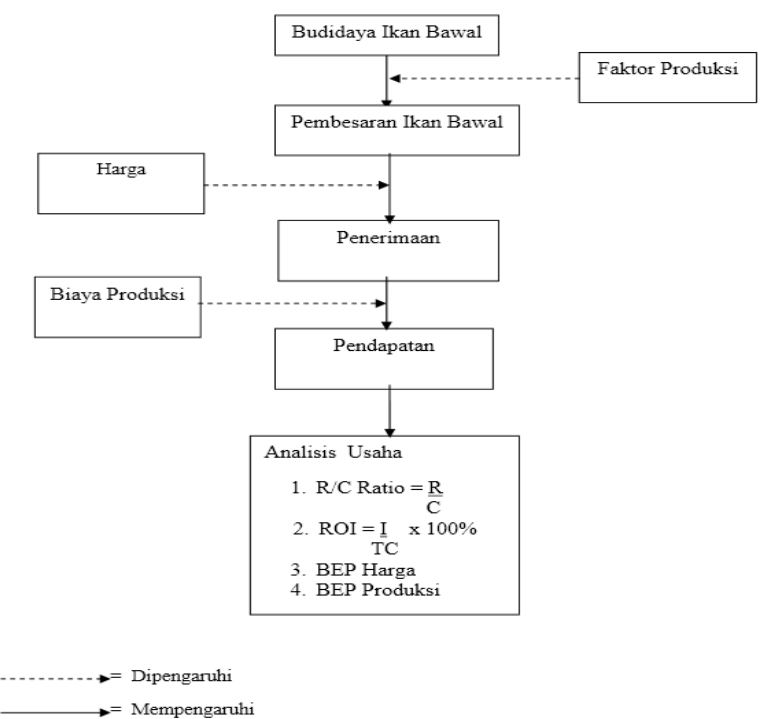

Gambar 1. Model pendekatan penelitian secara diagramatik

\section{METODOLOGI PENELITIAN}

\section{A. Tempat dan Waktu}

Penelitian ini telah dilaksanakan di Desa Sukosari Kecamatan Belitang Kabupaten OKU Timur. Penentuan lokasi penelitian dilakukan secara purposive atau sengaja, dengan pertimbangan bahwa di Desa Sukosari adalah salah satu Desa yang mengembangkan usahatani pembesaran ikan bawal serta wilayah tersebut memiliki jumlah populasi yang cukup dalam kriteria penelitian. Pengumpulan data dilokasi penelitian telah dilaksanakan pada bulan Februari 2015 sampai dengan selesai.

\section{B. Metode Penelitian}

Metode yang digunakan dalam penelitian ini adalah metode survei. Metode survei adalah penyelidikan yang diadakan untuk memperoleh fakta-fakta dari gejala-gejala yang ada dan mencari keterangan-keterangan secara faktual. Metode ini digunakan untuk mengetahui berapa besar biaya pada usahatani pembesaran ikan bawal yang digunakan petani berdasarkan data yang didapatkan dari petani sampel.

\section{Metode Penarikan Contoh}

Metode penarikan contoh yang digunakan dalam penelitian ini adalah metode purposive sampling (Sengaja) teknik penentuan sampel untuk tujuan tertentu saja. Purposive sampling adalah pengambilan sampel secara sengaja. Peneliti menentukan sendiri sampel yang diambil karena ada pertimbangan tertentu. Jumlah sampel pada penelitian ini diambil dengan 15 sampel karena di Desa Sukosari terdapat 15 sampel yang mengembangkan pembesaran ikan bawal.

\section{Metode Pengolahan Data}

Data yang diperoleh dari lapangan, diolah secara tabulasi dan matematis. Yang meliputi biaya produksi, penerimaan,dan pendapatan (Suratiyah, 2006). Untuk menghitung besarnya biaya produksi dapat menggunakan rumus matematis sebagai

$$
\mathrm{TC}=\mathrm{FC}+\mathrm{VC}
$$

Keterangan :

$\mathrm{TC}=$ Total Cost/Total Biaya Produksi (Rp/ Proses Produksi)
$\mathrm{FC}=$ Fixed Cost/Biaya Tetap $(\mathrm{Rp} /$ Proses Produksi)

$\mathrm{VC}=$ Variable cost/Biaya Variabel $(\mathrm{Rp} /$ Proses Produksi)

Untuk menghitung penerimaan dapat menggunakan rumus matetamtis sebagai berikut :

$$
\mathrm{TR}=\mathrm{P} \times \mathrm{Y} \text {. }
$$

Keterangan :

$\mathrm{TR}=$ Total Revenue $/$ Penerimaan $\quad(\mathrm{Rp} /$ Proses Produksi)

$\mathrm{Y}=$ Yield/Produksi (Rp/Proses Produksi)

$\mathrm{P}=$ Price $/$ Harga $(\mathrm{Rp} /$ Proses Produksi)

Dalam menghitung jumlah pendapatan dapat menggunakan rumus matetamtis sebagai berikut:

$$
\mathrm{I}=\mathrm{TR}-\mathrm{TC} .
$$

Keterangan :

I = Income/Pendapatan (Rp/Proses Produksi)

$\mathrm{TR}=$ Total Revenue/Penerimaan $(\mathrm{Rp} /$ Proses Produksi)

$\mathrm{TC}=$ Total Cost/Biaya Produksi $(\mathrm{Rp} /$ Proses Produksi)

Analisis R/C ratio untuk perbandingan antara penerimaan dengan total biaya perusahatani. $\frac{R}{C}$ ratio $=\frac{T R}{T C}$. 
Untuk menghitung keuntungan dari total biaya digunakan rumus matematis sebagai berikut :

BEP Penjualan $=\frac{F C}{1-\frac{\mathrm{AVC}}{\mathrm{P}}}$

BEP Produk $=\frac{F C}{P-A V C} \times 1$ Ekor

BEP Harga $=\frac{T C}{Y}$

Dimana :

$\mathrm{P}=\mathrm{Harga}(\mathrm{Rp} /$ produksi)

$\mathrm{AVC}=$ Average Cost (Rata-rata Biaya variabel)

$\mathrm{FC}=$ Biaya Tetap $(\mathrm{Rp} /$ Produksi)

$\mathrm{TC}=$ Total Biaya $(\mathrm{Rp} /$ Produksi $)$

$\mathrm{Y}=$ Produksi (Ekor)

Jika perhitungan tersebut diatas BEP sehingga bila rencana tersebut diaplikasikan pasti menguntungkan (Suratiyah, 2006). Untuk menghitung tingkat pengembalian modal menggunakan rumus berikut :

$$
\text { ROI }=\frac{I}{T C} \times 100 \text {. }
$$

Dimana :

$\mathrm{I}=$ Investas

$\mathrm{TC}=$ Total Cost

\section{HASIL DAN PEMBAHASAN}

1. Analisis Biaya Usahatani Prospek Pembesaran Ikan Bawal

Biaya adalah pengorbanan sumber ekonomi yang diukur dalam satuan uang yang telah terjadi atau kemungkinan akan terjadi untuk mencapai tujuan tertentu Mulyadi dalam Wibowo (2011). Biaya dalam kegiatan usahatani dikeluarkan oleh petani dengan tujuan untuk menghasilkan pendapatan yang tinggi bagi usahatani yang dikerjakan,dengan mengeluarkan biaya maka pertanian mengharapkan pendapatan yang setinggi-tingginya melalui peningkatan produksi.

Biaya tetap (Fixed Cost) Biaya yang relatif tetap jumlahnya dan harus dikeluarkan walaupun produk yang dihasilkan banyak atau sedikit. Biaya tidak tetap (Variable cost) . Biaya tidak tetap yang sifatnya berubah-ubah tergantung dari besar kecilnya produksi yang dihasilkan. Dalam hasil penelitian pembesaran ikan bawal di Desa Sukosari Kecamatan Belitang Kabupaten OKU Timur yang dikelompokkan ke dalam biaya tetap di antaranya adalah sewa lahan, dan penyusutan alat. Sedangkan untuk biaya variabel terdiri dari biaya benih ikan, pakan ikan, obatobatan, dan tenaga kerja.
Berikut ini merupakan komponen biaya yang dikeluarkan oleh petani dalam kegiatan usahatani pembesaran ikan bawal di Desa Sukosari Kecamatan Belitang :

a.Biaya Tetap

Biaya tetap yang digunakan pada produksi pembesaran ikan bawal diantaranya meliputi biaya sewa lahan dan biaya penyusutan alat yang dapat dilihat pada tabel berikut:

Tabel 3. Biaya Tetap pada Usahatani Pembesaran Ikan Bawal.

\begin{tabular}{llc}
\hline No & $\begin{array}{c}\text { Komponen } \\
\text { Pembesaran ikan } \\
\text { Bawal }\end{array}$ & $\begin{array}{c}\text { Rata-rata } \\
\text { (Rp/LG/Proses) }\end{array}$ \\
\hline 1. & Sewa Lahan & 3.888 .000 \\
2. & Penyusutan Alat & 673.425 \\
\hline & Total & 4.561 .425 \\
\hline
\end{tabular}

Sumber : Data Primer, 2015 diolah.

Kegiatan usahatani pembesaran ikan bawal di Desa Sukosari Kecamatan Belitang, dalam penggunaan input lahan sebagian besar memiliki status kepemilikan lahan sendiri, namun ada beberapa petani yang memiliki status kepemilikan lahan sewa, sehingga dalam kaidah usahatani semuanya dianggap sebagai lahan sewa. Karena untuk petani dengan status kepemilikan lahan sendiri juga melakukan pembayaran pajak lahan. Berdasarkan data di atas bahwa biaya ratarata sewa lahan pembesaran ikan bawal selama musim tanam per luas garapan memerlukan biaya sebesar Rp 3.888.000 /0,32 ha per produksi.

Penyusutan biaya peralatan yang dihitung meliputi penyusutan peralatan diantaranya terdiri atas cangkul, sabit, ember, pes, waring, saringan ikan, pipa paralon, selang buang, dan roli. Biaya rata-rata penyusutan alat yang digunakan saat proses pembesaran ikan bawal adalah $\mathrm{Rp}$ 673.425/produksi.

b. Biaya Variabel Usahatani Pembesaran Ikan Bawal.

Biaya variabel adalah biaya yang timbul dari pemakaian input tetap dan biaya yang dikeluarkan untuk membuat satuan-satuan ouput Sugiarto, Teddy Herlambang, dkk (2010). Biaya variabel yang digunakan dalam kegiatan usahatani di Desa Sukosari terdiri atas biaya bibit sampai dengan tenaga kerja.Besarnya biaya variabel yang dikeluarkan oleh petani dapat dilihat pada Tabel 4 sebagai berikut : 
Tabel 4. Rata-rata Biaya Sarana Produksi Usahatani Pembesaran Ikan Bawal.

\begin{tabular}{|c|c|c|c|}
\hline No & Komponen & Satuan & Pembesaran Ikan Bawal (Rpp Proses) \\
\hline 1. & Bibit Ikan Bawal & Rpproduksi & 1.478 .400 \\
\hline 2. & Pakan (Pelet) & RppProduksi & 3.436 .000 \\
\hline 3. & Klenteng & RppProduksi & 11.306 .667 \\
\hline 4. & Kapur Dolomit & Rpproduksi & 116.167 \\
\hline 5. & Bensin & Rpproduksi & 101.333 \\
\hline 6. & Obat-obatan & Rpp Produksi & 87.667 \\
\hline 7. & Tenaga Kerja & RppProduksi & 4.882 .375 \\
\hline & Jumlah Total & RppProduksi & 21.408 .608 \\
\hline
\end{tabular}

Sumber : Data Primer, 2015 diolah.

Berdasarkan uraian pada tabel di atas, dapat diketahui bahwa rata-rata penggunaan biaya variabel kegiatan usaha pembesaran ikan bawal di Desa Sukosari adalah Rp. 21.408.608/satu kali proses produksi. Responden mendapatkan benih ikan bawal yaitu dari tempat pemijahan ikan bawal yang ada di Desa Sukosari dengan biaya rata-rata $\mathrm{Rp} 1.478 .400 /$ proses produksi. Penggunaan pakan ikan yaitu pelet dan klenteng dengan biaya rata-rata Rp 11.306.667 untuk penggunaan pelet ikan, Rp 3.436 .000 penggunaan klenteng harga klenteng sangat mahal karena klenteng sulit diperoleh di daerah OKU Timur dengan harga $\mathrm{Rp} 3.200 / \mathrm{Kg}$, penggunaan klenteng sangat banyak dengan kisaran 2-5 ton per proses maka biaya yang dikeluarkan juga sangat tinggi.

Kapur dolomit digunaakan saat lahan akan diisi air sebagai penetral keasaman tanah agar ikan tidak banyak yang mati karena bau lumpur tanah sawah, biaya rata-rata pada penggunaan kapur dolomit sebesar $\mathrm{Rp}$ 116.167. Bensin digunakan untuk menghidupkan mesin sedot air dengan biaya rata-rata $\mathrm{Rp}$ 101.333. Obat-obatan digunakan sebagai vaksin ikan agar tidak terserang hama dan penyakit biaya rata-rata penggunaan obat-obatan Rp 87.667.

Biaya tertinggi kedua dalam usaha pembesaran ikan bawal yaitu pada tenaga kerja karena tenaga kerja sangat diperlukan dengan biaya rata-rata $\mathrm{Rp} 4.882 .375$ yang meliputi pembuatan kolam, penyebaran benih, pemberian pakan, dan perawatan. Berikut adalah tabel biaya rata-rata pada penggunaan tenaga kerja pembesaran ikan bawal.
Tabel 5. Biaya Rata-rata Penggunaan Tenaga Kerja Pembesaran Ikan Bawal.

\begin{tabular}{|c|c|c|c|}
\hline No & Uraian & Satuan & Biaya Penggunaan Tenagga Keja \\
\hline 1. & Pembuatan Kolam & RpProduksi & 3.224 .000 \\
\hline 2. & Penvebaran Benith & Rpproduksi & 8.375 \\
\hline 3. & Pemberian Pakan & Rpproduksi & 450.000 \\
\hline 4. & Biaya Perawatan Ikan & Rpproduksi & 1.200 .000 \\
\hline
\end{tabular}

Sumber : Data Primer, 2015 diolah.

Berdasarkan data hasil pada tabel, dapat diketahui bahwa jumlah biaya terbesar ada pada pengolahan lahan, usahatani dalam kegiatan pengolahan lahan dengan biaya sebesar $\mathrm{Rp}$ 3.224.000/ha pada pembesaran ikan bawal. Hal ini disebabkan karena kegiatan pengolahan lahan pembesaran ikan biasanya responden mengerjakan orang lain untuk mengolah lahan sawah yang akan di buat kolam. Sedangkan biaya tenaga kerja yang terkecil terdapat dalam kegiatan penyebaran benih, hal ini disebabkan karena dalam kegiatan penyebaran benih biasa dilakukan sendiri oleh petaninya secara langsung dengan biaya rata-rata $\mathrm{Rp} 8.375$. Biaya pemberian pakan dengan biaya rata-rata $\mathrm{Rp} 450.000$ dilakukan dengan tenaga kerja harian pria (HKP). Biaya perawatan dihitung dalam satu bulan dengan tenaga kerja pria (HKP) dengan biaya rata-rata selama 4 bulan Rp 1.200.000.

\section{Analisis Penerimaan dan Pendapatan Usaha} Pembesaran Ikan Bawal.

Usaha dikatakan menguntungkan apabila selisih antara penerimaan dengan pengeluarannya itu bernilai positif. Pendapatan usaha tersebut dianalisis dengan menggunakan konsep pendapatan atas biaya tunai dan pendapatan atas biaya total. Pendapatan atas biaya tunai diperoleh dari hasil pengurangan penerimaan terhadap komponen biaya-biaya yang dikeluarkan secara tunai dalam proses usahataninya. Besarnya ratarata pendapatan yang diterima oleh setiap reponden dalam kegiatan usaha yang telah dilakukan dapat dilihat pada tabel sebagai berikut : 
Tabel 6. Rata-rata Pendapatan pada Usaha Pembesaran Ikan Bawal.

\begin{tabular}{|c|c|c|c|}
\hline NO & Uraian & Satuan & Nilai \\
\hline 1. & Produksi Ikan & Kg Produksi & 3.546 \\
\hline 2. & Harga Ikan & $\mathrm{Kg}$ & 10.540 \\
\hline 3. & Penerimaan & Rp/ Produksi & 37.322 .467 \\
\hline 4. & Biaya Produksi & Rp/ Produksi & 25.970 .033 \\
\hline 5. & Pendapatan & Rp/ Produksi & 11.352 .433 \\
\hline
\end{tabular}

Sumber : Data Primer 2015, diolah.

Berdasarkan tabel di atas rata-rata hasil produksi ikan bawal sebesar $3.546 \mathrm{~kg} /$ produksi dengan harga rata-rata ikan bawal $\mathrm{Rp} 10.540 / \mathrm{kg}$ sehingga diperoleh penerimaan rata-rata $R p$ 37.322.467/produksi. Rata-rata biaya produksi yang dikeluarkan $\mathrm{Rp} 25.970 .033 /$ produksi dan memperoleh pendapatan rata-rata sebesar $\mathrm{Rp}$ 11.352.433/produksi.

\section{Analisis R/C dan ROI pada Usaha Pembesaran} Ikan Bawal.

Analisis R/C Ratio adalah suatu analisis yang digunakan untuk mengetahui tentang untung atau rugi dari suatu usaha dengan membandingkan antara total penerimaan dengan total biaya produksi. Berikut adalah hasil analisis $\mathrm{R} / \mathrm{C}$ ratio dan $\mathrm{ROI}$ pada usaha pembesaran ikan bawal :

Tabel 7. Analisis R/C dan ROI pada Usaha Pembesaran Ikan Bawal.

\begin{tabular}{ccc}
\hline NO & R/C (Rp) & ROI (\%) \\
\hline 1. & 1,4 & 42
\end{tabular}

Sumber : Data Primer 2015, diolah.

Analisis R/C ratio yang diperoleh dari pembesaran ikan bawal dalam 1 kali produksi dalammasa empat bulan sebesar Rp 1,4 yang berarti bahwa setiap satu rupiah yang dikorbankan akan diperoleh penerimaan sebesar $\mathrm{Rp} \quad 1,4$ demikian pembesaran ikan bawal dikatakan menguntungkan. Analisis ROI merupakan tingkat pengembalian modal dimana ROI pada usaha pembesaran ikan bawal sebesar $42 \%$, artinya bahwa setiap Rp 100.000,- modal usaha yang digunakan akan kembali sebesar Rp 42.000 dalam satu kali usaha.

\section{Break Event Point (BEP)}

Analisis titik impas (Break Event Point $=$ BEP) adalah suatu teknik analisis untuk mempelajari hubungan antara biaya (biaya tetap dan biaya variabel), keuntungan, dan volume kegiatan (Firdaus, 2009).

Analisis titik impas (BEP) terdiri dari BEP produksi dan BEP harga. BEP produksi dihitung dengan cara jumlah biaya produksi dibagi harga produk per unit, sedangkan BEP harga dihitung dengan cara jumlah biaya produksi dibagi jumlah produksi yang dihasilkan. Berdasarkan hasil perhitungan didapatkan nilai BEP produksi dan BEP harga dalam usaha pembesaran ikan bawal sebagai berikut :

Tabel 8. BEP Harga pada Usaha Pembesaran ikan Bawal.

\begin{tabular}{lcccc}
\hline No & $\begin{array}{c}\text { Total Biaya } \\
\text { Produksi }\end{array}$ & $\begin{array}{c}\text { Jumlah } \\
\text { Produksi } \\
(\mathrm{Kg})\end{array}$ & $\begin{array}{c}\text { BEP } \\
\text { Produksi } \\
(\mathrm{Kg})\end{array}$ & $\begin{array}{c}\text { BEP } \\
\text { Harga } \\
(\mathrm{Rp})\end{array}$ \\
\hline 1. & 25.970 .033 & 3.546 & 2.467 & 7.486 \\
\hline
\end{tabular}

Sumber : Data Primer 2015, diolah.

Berdasarkan tabel di atas, diketahaui ratarata BEP produksi adalah $2.467 \mathrm{~kg}$. Hal tersebut berarti bahwa dengan jumlah rata-rata produksi $2.467 \mathrm{~kg}$ pembesaran ikan bawal tidak mendapatkan keuntungan ataupun kerugian. Sehingga jika ingin mendapatkan keuntungan pembudidaya harus dapat menghasilkan ikan bawal lebih dari $2.467 \mathrm{~kg} /$ proses produksi. Sedangkan BEP harga diperoleh Rp 7.486/kg, yang berarti bahwa pembudidaya jika menjual ikan bawalnya dengan harga $\mathrm{Rp} 7.486 / \mathrm{kg}$ pembudidaya sudah mencapai titik impas yaitu tidak mendapatkan untung ataupun rugi, tetapi bila pembudidaya menjual ikan bawal tersebut dengan harga di atas harga BEP pembudidaya sudah memperoleh keuntungan.

\section{IV.KESIMPULAN DAN SARAN}

\section{A. Kesimpulan}

Berdasarnya hasil penelitian dan analisis yang telah dilakukan, maka dapat ditarik kesimpulan sebagai berikut:

1. Besarnya rata-rata biaya penerimaan dan pendapatan usaha pembesaran ikan bawal dalam masa produksi 4 bulan, diperoleh penerimaan dalam usaha pembesaran ikan bawal sebesar Rp 37.322.467/proses, 
sedangkan pendapatan dari usaha pembesaran ikan bawal Rp 11.352.433/proses .

2. Analisis $\mathrm{R} / \mathrm{C}$ ratio yang diperoleh dari pembesaran ikan bawal dalam 4 bulan sebesar 1,4 yang berarti bahwa setiap satu rupiah yang dikorbankan akan diperoleh penerimaan sebesar 1,4 demikian pembesaran ikan bawal dikatakan menguntungkan. Analisis ROI merupakan tingkat pengembalian modal dimana ROI pada usaha pembesaran ikan bawal adalah $42 \%$.

3. BEP produksi pada pembesaran ikan bawal adalah $2.467 \mathrm{~kg}$ maka usaha pembesaran ikan bawal tidak mendapatkan keuntungan ataupun kerugian dan BEP harga diperoleh Rp 7.486/kg pembudidaya sudah mencapai titik impas yaitu tidak mendapatkan untung ataupun rugi dalam pembesaran ikan bawal. Tetapi bila pembudidaya menjual ikan bawal tersebut dengan harga di atas harga BEP pembudidaya sudah memperoleh keuntungan.

\section{B. Saran}

Berdasarkan penelitian yang dihasilkan oleh penulis, dapat memberikan saran kepada responden ataupun kepada pembaca yang ingin melakukan usaha yaitu dapat mengoptimalkan hasil yang didapat, penting untuk memperhatikan tahap demi tahap berdasarkan referensi dan atau pengalaman yang sudah melakukan usaha pembesaran ikan bawal.

\section{DAFTAR PUSTAKA}

Chobiyah. 2001. Klasifikasi dan Deskripsi Ikan Bawal Air Tawar. http://klasifikasi-ikan bawal blog spot. com. Diakses 7 Januari 2015.

Dinas Kelautan dan Perikanan Sumatera Selatan. 2010. Diakses 7 Januari 2015.

Dinas Pertanian Tanaman Pangan, Perikanan dan Peterternakan Kabupaten OKU Timur. 2012. Diakses 7 Januari 2015.

Firdaus. 2008. Manajemen Agribisnis. Bumi Aksara. Jakarta.

Firdaus, M. 2009. Manajemen Agribisnis. Bumi Aksara. Jakarta.

Gitosudarmo, 2005. Teknik Proyeksi Bisnis. BPFE. Yogyakarta.

Hakim, A.N. 2003. Fakor Input dan Ouput Pada Produksi.http//www.Konsep_input_dan_out put.com. diakses pada 27/12/2013.

Hernanto, F. 1997. Ilmu Usahatani. Penebar Swadaya . Jakarta.
Ibrahim, Y. 2009. Study Kelayakan Bisnis. Rineka. Jakarta.

Kadariah, L. Karlina dan Gray, C. 1999. Pengantar Evaluasi Proyek. Fakultas Ekonomi Universitas Indonesia. Jakarta. 104 halaman.

Kordi. 2010. Budidaya Ikan Patin di Kolam Terpal. Lily Publisher. Yogyakarta.

Kotler, P. 2002. Manajemen Pemasaran, Prenhallindo. Jakarta.

Nazir, M. 2011. Metode Penelitian. Ghalia Indonesia. Bogor.

Nuraini. 2002. Pengantar Manajemen Agribisnis. Penebar Swadaya. Jakarta.

Pusat Data, Statistik dan Informasi.2013. Kementrian Kelautan dan Perikanan. Diakses 7 Januari 2015.

Rahardi, F. 2003.Mengubah Rintangan Menjadi Peluang Berinvestasi.PT. Agromedia Pustaka. Jakarta.

Rahim, A. dan Hastuti, D.R.D. 2007. Ekonomika Pertanian (Pengantar, Teori, dan Kasus). Penerbit Penebar Swadaya. Cimanggis, Depok, Jakarta.

Rasahan, C.A. 2000. Pembangunan Tanaman Pangan dan Hortikultura pada awal abad 21 (sebuah pengalaman). Dalam Pertanian dan Pangan. Bunga rampai Pemikiran menuju Ketahanan Pangan. Pustaka Sinar Harapan. Malang.

Saragih, B. 2001. Membangun Pertanian Perspektif Agribisnis. Masroh AH. Pertanian Mandiri. Jakarta.

Sjarkowi, F dan Sufri, M. 2004. Manajemen Agribisnis. CV. Baldad Grafiti Press. Palembang.

Sjarkowi, F. 2010. Manajemen Pembangunan Agribisnis. CV. Baldad Grafiti Press. Palembang.

Soekartawi. 2002. Analisis Usahatani. Penerbit Universitas Indonesia. Jakarta.

Soekartawi. 2011. Ilmu Usahatani dan Penelitian untuk Pengembangan Petani Kecil. Penerbit Universitas Indonesia. Jakarta.

Soetrisno, L. 2002. Paradigma Baru Menuju Pertanian Baru Sebuah Tujuan Sosiologis. Kanisius. Yogyakarta.

Sucipto, A. dan E. Prihartono. 2005. Pembesaran Nila Merah Bangkok di Karamba Jaring Apung, Kolam Air Deras, Kolam Air Tenang dan Karamba. Penebar Swadaya. Jakarta.

Sugiarto, Tedy Herlambang, dkk. 2010. EKONOMI MIKRO Sebuah Kajian 
Kompreherensif. PT Gramedia Pustaka Utama. Jakarta.

Wibowo, S. Larasati. 2012. Analisis Efisiensi Alokatif Faktor-Faktor Produksi Dan Pendapatan Usahatani Padi (Oryza Sativa L.). Skripsi pada Jurusan Sosial ekonomi Pertanian Program Agribisnis Universitas Brawijaya Malang. Malang. (tidak dipublikasikan).

Yulinda, E. 2012. Analisi Finansial Usaha Pembenihan Ikan Lele Dumbo (Clarias gariepinus) Di Kelurahan Lembah Sari
Kecamatan Rumbai Pesisir Kota Pekanbaru Provinsi Riau.(tidak dipublikasikan).

www. Wikipedia Indonesia. com. http//teknik budidaya ikan bawal. Diakses tanggal 07 Januari 2015.

http://wizii.blogspot.com/2012/03/analisa-breakevent-point-bep. $\mathrm{html} / /$ analisa break event point (BEP). Diakses tanggal 07 Januari 2015. 